\title{
Otro poeta en Nueva York. Gilberto Owen en Los ingrávidos (2011) de Valeria Luiselli ${ }^{1}$
}

\author{
Another Poet in New York. \\ Gilberto Owen in Los ingrávidos (2011) by Valeria Luiselli
}

\author{
KRISTINE VANDEN Berghe \\ Université de Liège \\ Kristine.Vandenberghe@uliege.be
}

NiCOLAS LiCATA

Université de Liège

N.Licata@uliege.be

RESUMEN: En la primera novela de Valeria Luiselli, titulada Los ingrávidos (2011), el protagonismo de Gilberto Owen ilustra el deseo de la autora de dar una renovada visibilidad a ese escritor mexicano y, al mismo tiempo, de crearse una auto-imagen que legitime su propia actividad de escritora. Desarticulación del contenido, intertextualidad sostenida y recurrencia de la reflexión metaficcional, estos rasgos que presenta la práctica novelística de Luiselli coinciden con la de Owen y sugieren que reivindica un parentesco literario que la sitúa en una familia de escritores mexicanos de vanguardia. La filiación se hace aún más explícita porque Luiselli convierte a Owen en personaje literario de la novela (no sin exagerar algunos de los rasgos del poeta asociados frecuentemente a la figura del artista, como el alcoholismo o el fracaso relacional) y lo introduce como su propio doble.

\author{
Palabras Clave: \\ Gilberto Owen; \\ Valeria Luiselli; \\ autoficción; \\ vanguardia literaria.
}

\begin{abstract}
KEYWORDS: ABSTRACT: In the first novel written by Valeria Luiselli, Gilberto Owen; Los ingrávidos (2011, translation into English: Faces in Valeria Luiselli; the crowd), the prominence of Gilberto Owen as a Self-fiction; character indicates that Luiselli wishes to give a reAvant-garde Literature. newed visibility to this Mexican artist and, at the same
\end{abstract}

1 La redacción de este artículo ha sido posible gracias a una estancia de investigación de Kristine Vanden Berghe en el Centro de Investigaciones sobre América Latina y el Caribe de la Universidad Nacional Autónoma de México. Agradecemos al doctor Enrique Camacho Navarro la invitación y el apoyo.

Literatura Mexicana |XXXI-1 | 2020 | 155-178 | DOI: 10.19130/iifl.litmex.31.1.2020.1150 
time, to create a self-image that legitimates her activity as a writer. Disarticulated content, continuous intertextuality and recurring metaliterary reflection, various of the commonalities which link up Luiselli's poetic practice with that of Owen suggest that she vindicates a literary relationship that situates her in a family of Mexican avant-garde writers. This affiliation is even more explicit in the novel, because Luiselli turns Owen into a literary character (not without exaggerating some of the poet's traits that are often associated with the figure of the artist, such as alcoholism or relational failure) and introduces him as her own double.

recepción: 11 septiembre 2018 aceptación: 08 enero 2019

A finales de los años veinte del siglo pasado, el poeta andaluz Federico García Lorca y el escritor sinaloense Gilberto Owen coincidieron en la ciudad de Nueva York. Aunque es poco probable que sostuvieran una colaboración literaria o, incluso, una verdadera amistad, la producción artística de ambos llegó a conectarse por iniciativa del cineasta mexicano Emilio Amero, en aquel entonces también residente en Nueva York. Ambos poetas vuelven a coincidir, pero esta vez como personajes, en la primera novela de Valeria Luiselli, titulada Los ingrávidos (2011). En ella sobre todo Owen es un personaje importante y su protagonismo ilustra el deseo de Luiselli de dar una renovada visibilidad a ese escritor mexicano, gran poeta de los Contemporáneos pero al mismo tiempo uno de los menos conocidos entre ellos. Asimismo, al asociarse con él e, incluso, al representarlo como un doble suyo, Luiselli se crea una auto-imagen que la sitúa en cierta línea de la literatura mexicana y legitima su actividad de escritora.

\section{Federico García Lorca y Gilberto Owen en Nueva York}

Cuando trata sobre la estancia de García Lorca en Nueva York en los años 1929 y 1930, la crítica suele destacar algunos textos suyos que se originaron o se escribieron allí y subrayar ciertos estados de ánimo del poeta. Tras una profunda crisis personal, su pasaje por América representó una expe- 
riencia estremecedora que lo llevó a desarrollar nuevos caminos de expresión que desembocaron en poemas herméticos y en versos que daban cauce a su indignación por el trato dado a los negros. El mundo creado en Poeta en Nueva York (1930), por ejemplo, en gran medida carece de anécdotas; al contrario, es un universo de sueños donde no importa el significado exacto sino el efecto evocador, donde se sugieren sensaciones y se crea una atmósfera de angustia y dolor.

Bastante menos conocido que este poemario de índole surrealista es otro texto repleto de imágenes de esta raigambre que García Lorca escribió durante la misma estancia. Titulado "Viaje a la luna", lo habría redactado para el pintor y cineasta mexicano Emilio Amero que, en aquel entonces, también residía en Nueva York. ${ }^{2}$ El texto fue dado a conocer primero en inglés en la revista New Directions en 1961 y treinta años más tarde, en versión facsimilar, por la editorial Pre-textos. Guillermo Sheridan, quien dedicó un ensayo lleno de hipótesis interesantes a su génesis, afirmó al respecto: “En 1937, poco después del asesinato del poeta, Amero anunció en México que filmaría su guion como un homenaje. Intentó hacerlo, pues quedan algunos fotogramas de la primera escena, pero al parecer no logró terminarla" (105). Según dice Antonio Monegal, prologuista de la edición de 1994, se trata de uno de los "textos más rodeados y preñados de misterio de la obra lorquiana, de los que más vicisitudes han pasado, más problemas textuales presentan y a la vez más oscuros son, que resultan ser el producto de un viaje del poeta: ese viaje físico a Nueva York en 1929 que marca también una mudanza en su trayectoria estética" (8).

Aún menos conocido que este texto de García Lorca es el hecho de que se trataba posiblemente de la continuación de un trabajo del escritor Gilberto Owen quien residió en Nueva York entre 1928 y 1930 como empleado del servicio consular mexicano. ${ }^{3}$ Aunque los contornos precisos de

\footnotetext{
2 No obstante, no se alude al guion del "Viaje a la luna" en el catálogo de la Exposición Amero. 25 nuevas fotografías (1932).

3 Dice Sheridan sobre el trabajo de Owen en Nueva York: "en alguno de esos rascacielos, en el consulado de México, Gilberto Owen llevaba un par de años dedicando sus mañanas a redactar las filiaciones medias de los marinos norteamericanos cuyos oxidados cargueros harían escala down Mexico way, en los astrosos puertos de Veracruz y Tampico" (109). Según el mismo crítico, Owen se refería a su incorporación al servicio exterior mexicano con las palabras de "huida" o "salida" (80). Por su parte,
} 
la relación que existe entre "Viaje a la luna" de García Lorca y el texto de Owen titulado "El río sin tacto" carecen de claridad, Guillermo Sheridan formula una serie de conjeturas prudentes al respecto:

creo que Amero estaba empeñado en realizar una película sobre la idea original de Owen y puso a trabajar a García Lorca en otra de sus secciones. Conjeturo que luego de ver 777 Amero le muestra a García Lorca el esquema de la película más ambiciosa en que ha estado trabajando (con Owen en 1928), platican del asunto y García Lorca escribe Viaje a la luna, ya como un proyecto distinto, aunque con tópicos similares, ya como una secuencia del mismo argumento de Owen y Amero, que correspondería a lo que el "Hombre de la Luna" vive luego de su caída en Nueva York. Amero entonces habría retrabajado el guion de García Lorca — como retrabajaba el de Owen-y lo habría adaptado aún más, como resulta evidente de las numerosas alteraciones que presenta la versión publicada en New Directions en 1961 ante la edición de Monegal de 1994 (122).

Del texto de Owen, al que éste no se refería en términos de guion sino de "escenario" (Sheridan: 105) aparecieron algunas secuencias en la revista Contemporáneos en 1933 donde se publicaron como poesía. Una de ellas se titulaba "Hombre de la luna", un tópico que retoma el de "río sin tacto" que Sheridan (213) interpreta como una metonimia de la luna y que será retomado luego por García Lorca en su Viaje a la luna. Otro aspecto que hace que Sheridan crea en la hipótesis de una estrecha intertextualidad entre ambos textos es el imaginario de Nueva York, ciudad sexualizada por ambos poetas: "en Owen, una disolvencia quiere que el mapa de Manhattan se convierta en falo, mientas que las luces diagonales de la avenida Broadway se convierten en vagina en el guion de García Lorca" (124).

El andaluz y el mexicano se conocieron en el grupo de hispánicos en Nueva York pero no establecieron una amistad relevante, lo cual se puede inferir, por ejemplo, del hecho de que García Lorca no se refirió nunca a

Claudio Vázquez Pacheco considera que es difícil entender por qué Owen buscó salir al extranjero y dejar en México a sus amigos y a Clementina Otero, su amada de aquel entonces. Según él, "la única justificación es el deseo de viajar. Nada lo detiene y pocos días después pisa el suelo de Nueva York, bajo el cargo de escribiente de primera en el Consulado de México de esa ciudad. Este es el principio de una larga ausencia" (33). Para otras hipótesis al respecto de su "huida", véase Quirarte 2007: 65. 
Owen (Sheridan: 109). En cambio, en una carta fechada el seis de julio de 1948 desde Filadelfia y destinada a Josefina Procopio, Owen comienza contando una anécdota refiriéndose al andaluz: "Yo he tenido amigos con los nombres más raros. Recuerdo que García Lorca me decía: 'Qué raro que me Ilamen Federico', y yo a veces me ruborizo cuando tengo que confesar que me llamo Gilberto" (279-280). Se trata de una de las cartas escritas por el poeta mexicano que constituyen una parte significativa de su producción literaria (Stanton: 743) y que incluyen una serie de referencias interesantes a la ciudad de Nueva York, a Manhattan y al subway.

Es probable que Valeria Luiselli se haya basado en ellas para crear su historia acerca de la estancia neoyorquina de Owen. Que las conociera se deduce del breve comentario que escribió sobre Owen en Letras Libres en enero de 2009. En él comienza por referirse a una carta que Owen escribió desde Nueva York a Celestino Gorostiza y que comentaremos más adelante. Pero en este texto también se refiere a la prosa lírica del poeta, entre otras a su novela titulada Novela como nube (1928). La correspondencia neoyorquina y dicha novela son dos hipotextos significativos de su propia novela, Los ingrávidos, cuya trama pasa en gran medida en la ciudad de Nueva York y que Christopher Domínguez Michael sintetiza como sigue: "Mediante un falso desorden narrativo, un rompecabezas fácil, Los ingrávidos es la historia de una pequeña estafa literaria en Nueva York, cuyo propósito es dar de alta entre los raros del momento al poeta sinaloense Gilberto Owen, a cuyo fantasma, ella misma mínima o minimalista, le da vida" (69). Queda claro pues que la figura del escritor integrante del "grupo sin grupo" conocido como los Contemporáneos desempeña un papel central en la trama. Si Luiselli lo eligió entre los escritores mexicanos es, sin duda, porque residió, como ella, en Nueva York y, más fundamentalmente, porque quiso realzar las coincidencias entre su propia práctica poética y la de su paisano y sugerir ciertas semejanzas entre ella misma y la persona de Gilberto Owen.

\section{Owen y Luiselli: prácticas poéticas}

Los parecidos entre la obra de Owen y Los ingrávidos son llamativos y la novela de Luiselli se puede cotejar, por ejemplo, con Novela como nube 
que Owen terminó justo antes de irse a Nueva York y que desde el título ya alude a la ingravidez. ${ }^{4}$ Por una parte ambos textos comparten características estructurales que los emparentan con la vanguardia; por otra parte, se parecen por la manera en la que se posicionan dentro de una tradición literaria nacional y, al mismo tiempo, la exceden.

Entre los rasgos vanguardistas principales de Novela como nube (González Muñiz: 167-168), se debe señalar la desarticulación de los contenidos anecdóticos, el diluir de la trama. Por la falta de una anécdota clara, Paola Velasco ha sugerido que "quizás haya que leer Novela como nube así, precisamente, como una nube. Las imágenes crípticas, las vaguedades del asunto y los personajes nos entregan también una novela vaporosa" (191). ${ }^{5}$ De una manera paralela se puede proponer que Los ingrávidos se lea como una novela ingrávida ya que tampoco en ella hay una trama clara y elaborada por cuanto domina una lógica de índole digresiva y fragmentaria. Ilustra que Luiselli descarta que la anécdota deba dominar sobre el estilo, una valoración que ha expresado en algunos textos suyos de no ficción, por ejemplo en su juicio severo sobre la premio Nobel Toni Morrison: "Morrison escribe pensando en temas: una novela se tiene que tratar de algo, hablar de algo, enseñar algo, dice ella misma en varias entrevistas y ensayos. En principio, parece sensato. Pero, a nivel del texto mismo, darle esa centralidad a los grandes temas [...] puede ir en detrimento de otras cosas más importantes para la coherencia del mundo que

${ }^{4}$ La editio princeps de la novela menciona lo siguiente en su colofón: "Este segundo volumen de las 'Ediciones de Ulises' se acabó de imprimir en los talleres de la editorial CVLTVRA, en la Ciudad de México, el día treinta de junio de mil novecientos veintiocho". Según Vicente Quirarte, Owen salió para Nueva York a principios de 1928 (2007: 69). Cabe recordar aquí el dato brindado por el mismo investigador de que Novela como nube iba a Ilamarse originalmente Muchachas (2004: XII). Quirarte Ilama la atención sobre la importancia de este tema entre los Contemporáneos: "las novelas de Torres Bodet y Villaurrutia tienen también, como protagonistas, a jóvenes personajes femeninos, mujeres inteligentes, sensibles y pensantes, pero al mismo tiempo inasibles, etéreas, peligrosas, rebeldes al dominio varonil" (XII). Se trata de sendos rasgos de la protagonista de Los ingrávidos.

5 Uno de los capítulos del primer tomo de la Antología de la narrativa mexicana del siglo xx de Christopher Domínguez Michael se titula "Novelas como nube" e incluye fragmentos de La señorita Etcétera de Arqueles Vela, Novela como nube de Owen, Dama de corazones de Xavier Villaurrutia, El joven de Salvador Novo y Margarita de Niebla de Jaime Torres Bodet (1989: 547). 
una novela erige" (2009b: 59). ${ }^{6}$ Un segundo rasgo característico de la obra de Owen es la sostenida intertextualidad que multiplica las posibilidades de lectura. Al respecto, Tomás Segovia ha insistido en las "constantes alusiones librescas en la obra de Owen" (22) donde se crea un "mundo donde libros y acontecimientos no pueden separarse" (23) mientras Vicente Quirarte habla de "una prosa poblada de alusiones culteranas, mayoritariamente literarias" (2007: 56). Luiselli comparte este gusto por las referencias literarias y las alusiones a otros escritores y textos. Sobre el particular en Los ingrávidos, María Pape ha señalado con razón que su "gran cantidad indica la multiplicidad de coordenadas en relación con las cuales se puede pensar[la]" (193).

En Owen la marginación de la trama y la intertextualidad también son el efecto de la presencia de la práctica metaficcional que comenta el propio proceso de escribir. Este tercer rasgo de vanguardia a menudo viene acompañado por la abundancia del material autobiográfico: el narrador se trasmuta en autor y personaje, lo cual causa extrañamiento en el lector ya que torna difusa la distinción entre personajes, narradores y autores. Tomás Segovia incluso ha dicho al respecto que, ya que Owen no era tan conocido entre los poetas de su generación, los críticos se suelen basar en sus textos para hacer deducciones sobre su vida. ${ }^{7}$ De hecho, según el mismo Segovia, el escritor iba "identificándose él mismo, o identificando

6 La importancia de la forma y el cuidado con el que construye el puzle de Los ingrávidos se deduce asimismo de una comparación entre distintas ediciones de la misma novela. Ningún elemento peritextual lo indica, y sin embargo, entre la primera edición y la cuarta, que hemos utilizado, el orden de los fragmentos se ha alterado de una manera drástica.

7 "De todos los poetas mexicanos de su generación, Gilberto Owen es probablemente uno de los menos conocidos, tanto en su país como en otros [...]. Casi todo lo que puede saberse de su vida es lo que se encuentra en ese breve prólogo y en algunos escasos pasajes epistolares reproducidos en el mismo volumen. Lo demás habría que buscarlo en su poesía. Y casi podría decirse que lo demás es poesía, porque la trasmutación poética de la materia biográfica es precisamente, me parece, lo más profundo que hay en la obra de Gilberto Owen" (Segovia: 7). Incluso, desde el punto de vista de Vázquez Pacheco: "Hoy en día es difícil encontrar la línea que divide las dos vidas de Gilberto Owen, diferenciar la zona que corresponde a los hechos biográficos de la que llena la literatura es una necesidad que se impone ante la confusión" (17). Según Quirarte, "toda su poesía está poblada de alusiones autobiográficas, pero cada uno de sus actos aparece transformado por su 'tortura de aprendiz de magia'" (2007: 16). 
los episodios de su biografía, con los personajes y las situaciones de los mitos y leyendas, o incluso de obras literarias bastante recientes" (26). Así creaba personajes que eran dobles suyos, como por ejemplo Ernesto en Novela como nube, que desde la perspectiva de Sheridan (44) era su álter ego. Por último, construía personajes con su propio nombre, como es el caso del "poeta Gilberto" en "Examen de pausas" (Owen: 187). De esta forma, Owen aparece como un practicante precoz de lo que hoy en día se suele llamar autoficción, género donde las instancias del autor, narrador y personaje coinciden en un texto que, no obstante, se presenta como ficción. Y ya que en su obra los guiños autobiográficos se combinan con una fuerte presencia de mecanismos metaficcionales, ambos generando ambigüedad, más precisamente se arrima a lo que Vincent Colonna ha Ilamado autoficción especular (2004).

Metaficción y autoficción también están masivamente presentes en Los ingrávidos que es una self-begetting novel (Kellman 1980) o una "novela de la novela" (Orejas 2003), es decir una novela haciéndose cuyo novelar se comenta en el mismo momento de escribirla. La narradora intenta escribir un libro sobre Owen y al mismo tiempo uno que cuente su propia vida. No es fácil con un niño y un bebé ni tampoco con un marido que le recrimina constantemente ya sea la falta de veracidad de lo que escribe, ya sean algunos episodios de su vida pasada que comenta en el libro que está escribiendo y que no le agradan, haciendo abstracción así del principio de la distancia entre escritura y realidad. De esta manera el texto que incluye distintos niveles diegéticos está repleto de comentarios y de reflexiones sobre qué es la literatura, cómo se lee y sobre el proceso de escribir, que deshacen la ilusión novelesca. Al mismo tiempo, esta narradora (Owen es otro), aunque no tenga nombre, incluye tantos rasgos de la autora que su historia se puede leer en clave autoficcional. Es mexicana, su marido también escribe, es madre, ha vivido en Nueva York y en México, se interesa por Owen sobre quien intenta escribir una novela, entre otros datos. Y aunque haya hechos que no concuerdan, el pacto ambiguo no se ve destruido por ellos. También la novela de Luiselli se allega pues a la autoficción especular en la medida en que en ella se cruza la metaficción con un pacto de lectura que postula simultáneamente el carácter autobiográfico y la índole ficcional del texto. 
Mediante las alusiones a Owen que llaman la atención sobre los rasgos que Los ingrávidos comparte con su obra, Luiselli reivindica un parentesco literario que la sitúa en una familia de escritores de vanguardia. En la reseña ya mencionada de Domínguez Michael, éste la relaciona de manera pertinente con el nouveau roman francés y Sigifredo E. Marín asoció la obra de Owen con esta misma corriente de la literatura francesa (68). Esta relacionabilidad de ambos escritores con tendencias literarias foráneas no impide, sin embargo, que se sitúen al mismo tiempo a sí mismos en una tradición hondamente mexicana. En cuanto a Luiselli, la protagonista y una de las narradoras de su novela es una mujer joven que habla en primera persona y que se mudó de Nueva York a la Ciudad de México. Sitúa su pasado en Nueva York, mientras que vive su presente en México; Nueva York es el espacio de su juventud, de los vaivenes entre pisos y los amores pasajeros, mientras que en México es más sedentaria, trabaja en casa y debe ocuparse de un marido y dos hijos; en comparación con el espacio mexicano de la maternidad y responsabilidad, Nueva York se presenta por lo tanto como el espacio por excelencia de la ingravidez, la ligereza, el movimiento, en fin, la liquid modernity tal como ha sido definida por Zygmunt Bauman (2000).

Sin embargo, si la narradora/autora se desplaza ligera en Nueva York, no es que lo haga sin bagaje. Porque, precisamente, la acompañan sus numerosas lecturas, también y sobre todo, de escritores mexicanos. Por lo tanto, el personaje del yo narrador, joven escritora mexicana, doble de Valeria Luiselli, que encarna el cosmopolitismo, el desarraigo y la movilidad, al mismo tiempo se encuentra muy arraigado en la tierra y la tradición mexicanas mediante las referencias — en distintos niveles diegéticos del texto- a Owen pero igualmente a otros escritores mexicanos: a Salvador Novo y José Juan Tablada, otros dos contemporáneos mencionados explícitamente, a Carlos Fuentes, mediante la presencia del naranjo, o a Juan Rulfo. Si la referencia a este último es clara dentro de la novela a través del personaje (secundario) de Do Preciado, ${ }^{8}$ también lo es en el discurso de la

8 En el texto de Luiselli, también Owen se encuentra asociado en cierta medida al autor de Pedro Páramo. El personaje afirma que, desde los años 1950: "quiero escribir una novela que sucede en una casona en la ciudad de México y en el Nueva York de mi juventud. Todos los personajes están muertos, o afantasmados, pero no lo saben. 
escritora sobre su libro, porque admite que se inspiró en la estructura de Pedro Páramo para armar la trama de Los ingrávidos: "Cada vez que llueve sabemos que cambiamos de un tiempo a otro. A partir de esa lectura deseché el mecanismo de cambios temporales y confié en el lenguaje cada vez que cambiaba de un tiempo a otro" (Usi: s.p.). Es más, la lectura de la novela de Rulfo fue una "iluminación": "Hace un tiempo tuve que hacer un guion para niños acerca de Pedro Páramo y estuve leyendo muchas entrevistas. En una de ellas Rulfo dice que había sentido una gran libertad cuando se dio cuenta de que los personajes estaban muertos, entonces pudo usar el tiempo y el espacio con una flexibilidad absoluta. Yo dije 'claro', fue como un momento de iluminación" (Barbosa Vera y Scofaulos: s.p.). ${ }^{9}$

Luiselli se incluye en el devenir de la literatura mexicana de un modo paradójico, asociándose mediante Owen con uno de los menos "mexicanizables" de los escritores nacionales. ${ }^{10}$ Así, es consabido que Owen, como los demás Contemporáneos, tomaba su distancia de cierta tradición artística nacional a la que calificaba de paupérrima y ensordecedora y que asociaba con el romanticismo americano y el folclore. En "Motivos de Lope de Vega. Suma de ocios", escribió:

yo había elegido este cautiverio [de Góngora], precisamente como un refugio al huir de la improvisación y de la facilidad que me repugnaban en ejemplos más cercanos a mí, geográfica y temporalmente: yo nací huyendo del Chocano a voz en cuello, de nuestro paupérrimo y ensordecedor romanticismo america-

Me contó Salvador Novo que hay un joven escritor en México que está haciendo algo parecido" (2014: 136). Es probable, como advierte también González Arce (266), que el joven escritor en cuestión sea Juan Rulfo. Tanto el tema de la novela como las fechas coinciden (Pedro Páramo fue publicada en 1955, después de una larga gestación). Para la autora de Los ingrávidos, sería otra forma de situarse en la continuidad de Rulfo.

9 Anthony Stanton ha señalado el mismo "libre fluir temporal" en la obra de Owen, proveniente de la estética surrealista (744).

$10 \mathrm{Al}$ respecto, Roxana Elvridge-Thomas sintetizó: “aquel grupo [los Contemporáneos] animado por la atracción hacia la poesía y el deseo de encontrar para ella nuevas perspectivas, saltó las barreras que levantaba un país donde la Revolución triunfante imponía una estética figurativa y nacionalista, para crear obras alejadas de las circunstancias inmediatas y, por eso mismo, universales y atemporales, contemporáneas de todos los hombres" (7). 
no, de la baratija de nuestro folclore, empapado éste de las dos cosas que más repugnaban mi espíritu: las lágrimas y la sangre (201).

Mientras Owen en este texto lamenta que esta tendencia se manifieste con tanta constancia en la creación literaria mexicana, Luiselli, en un ensayo que publicó en 2012 en la revista Nexos, arremetió principalmente contra una inclinación parecida en la crítica nacional. Si ésta le parecía mala era, precisamente, porque se centraba en los mismos rasgos y el mismo tipo de textos atacados por Owen. El romanticismo americano y el folclore, las lágrimas y la sangre, en el texto de Luiselli se Ilaman la moda de lo marginal y del subalterno y cobran la figura de la ficción sobre el narcotráfico. Tal y como lo hacía Owen muchas décadas antes, se preguntaba entonces: “¿Cómo es posible que en México sigamos —los lectores y críticos más jóvenes - obsesionados con explicarnos a nosotros mismos a través de fijar una identidad nacional reducida a unos cuantos rasgos burdos?" (2012: s.p.). Las referencias a Owen demuestran que Luiselli ha elegido su campo y su filiación: la literatura mexicana de vanguardia que no se siente atraída por los temas considerados más nacionales pero que gusta de aludir a ellos oblicuamente en textos donde la anécdota pierde su nitidez a favor de una voluntad de forma.

Hay una serie de coincidencias más puntuales entre la obra de Owen y la novela de Luiselli, de las que nos limitamos aquí a señalar algunas, pero que merecen ser estudiadas con mayor profundidad. En ambas destaca el campo semántico de lo horizontal versus lo vertical. En Obras, lo vertical se comenta, entre otros textos, en aquellos citados en las páginas 90-91, 109, 125, 137, 138. En Los ingrávidos es un importante leitmotiv (captado desde el mismo título de la novela así como en la frase "una novela horizontal, contada verticalmente", que aparece en las páginas 66 y 74 y se repite en la 128, pero invertida: "una novela vertical, contada horizontalmente"). Otro leitmotiv es el naranjo muerto, que hace pensar en el cuento de Carlos Fuentes titulado "El naranjo" pero que posiblemente también remite al tema del árbol en la obra de Owen. Guillermo Sheridan dijo al respecto: "Son muchas las ocasiones, a lo largo de la obra de Owen, tanto en prosa como en verso, en que las raíces del árbol están en el aire, el cielo es el suelo, peces son las aves y olas las nubes" (78-79) y 
profundizó en el sentido de la imagen: "Desde sus primeros poemas, Owen acudió a los árboles y a los arbustos para urdir imágenes de signo negativo referidas a fracasos afectivos [...]. Además de la relación legendaria entre los árboles sagrados y los bardos, a Owen le gusta representarse como un retoño a la sombra del árbol-padre, una criatura desprotegida que echa de menos al padre ausente, un 'párvulo que se siente solo'" (45). Que Owen utilizara el árbol de manera metafórica, incluso en sus ensayos sobre literatura, lo ilustra el texto titulado "Biombo', poemas de Jaime Torres Bodet": "Torres Bodet sacude en octava cosecha la más formal y sazonada, su árbol — sonaja y antorcha - de poesía, enraizado, recto y frondoso. Nos gustaría que se tomara esto un poco literalmente, porque si otros poetas se solazan con el escorzo fracasado de palmera que es el cohete, en éste se acusa una conciencia sostenida en el tallo, no para continuarse en orden sucesivo, sino para renovarse, para remozarse toda en el fruto nuevo de sabor inconfundible" (215). En su primer libro, Papeles falsos (2010), Luiselli ya conectaba con esta carga emocional asociada al árbol: unía su integración fracasada en México al recuerdo de la desaparición del árbol que su padre había hecho plantar en su honor: "Si mi palmera no había arraigado, tampoco yo llegaría a ser nunca una heroica ciudadana [...]. Nunca echaría raíces en la ciudad de México" (103).

\section{Owen y Luiselli: personajes reflejados}

Los ingrávidos no sólo evoca masivamente la poética de Owen sino que también lo crea como personaje, un personaje que es al mismo tiempo uno de los narradores en la novela. El que aparezca como doble de la narradora, que a su vez es un doble de la autora, estimula a que se aborden juntos y se comparen ambos personajes, el poeta Owen y la narradora-escritora mexicana en Nueva York. El personaje Ilamado Gilberto Owen incluye rasgos de la persona histórica con el mismo nombre: es un mexicano que vive en Nueva York, está casado y tiene dos hijos, es un funcionario al que le gusta escribir y al que vemos en compañía de otros escritores y artistas, entre ellos García Lorca. Se desplaza en metro, un medio de transporte que le fascina, tiene una experiencia sexual significativa con una sueca, y escribe cartas a sus amigos en México, entre otros hechos 
verídicos. ${ }^{11}$ Sin embargo, Luiselli exagera algunos de ellos hasta tal punto que llega a desvirtuarlos $y$, sobre todo, las exageraciones contribuyen a subrayar la condición paratópica del escritor y, así, de ella misma ya que ambos personajes se reflejan.

El concepto de paratopía ha sido elaborado por el lingüista francés Dominique Maingueneau (2004) con el fin de determinar la especificidad de los discursos religiosos, filosóficos y literarios. Sugiere que una característica de este tipo de discurso es ser paratópico, es decir que se enuncia desde un lugar basado en una doble imposibilidad: la de cerrarse sobre sí mismo y la de confundirse con la sociedad ordinaria del común de los mortales. Para Maingueneau, los medios literarios están hechos de fronteras: se sitúan en el límite entre la inscripción en los funcionamientos de la sociedad general, y la sumisión a fuerzas que superan toda economía humana. Por consiguiente el escritor tiene un estatus paradójico:

Celui qui énonce à l'intérieur d'un discours constituant ne peut se placer ni à l'extérieur ni à l'intérieur de la société : il est voué à nourrir son œuvre du caractère radicalement problématique de sa propre appartenance à cette société. Son énonciation se constitue à travers cette impossibilité même de s'assigner une véritable 'place'. Localité paradoxale, paratopie, qui n'est pas l'absence de tout lieu, mais une difficile négociation entre le lieu et le non-lieu, une localisation parasitaire, qui vit de l'impossibilité même de se stabiliser. Sans localisation, il n'y a pas d'institutions permettant de légitimer et de gérer la production et la consommation des œuvres, mais sans dé-localisation, il n'y a pas de constituance véritable (72). ${ }^{12}$

De esta forma la paratopía no sólo caracteriza la condición del texto literario, sino también la del escritor. Éste se convierte en creador literario

11 Para una biografía detallada del escritor, véase Vázquez Pacheco 2015.

12 "Quien enuncia dentro de un discurso constituyente no puede ubicarse ni el exterior ni en el interior de la sociedad: está condenado a alimentar su obra del carácter radicalmente problemático de su propia pertenencia a dicha sociedad. Su enunciación se constituye mediante esa imposibilidad misma de asignarse un verdadero 'lugar'. Ubicación paradójica, paratopía, que no es la ausencia de lugar, sino una difícil negociación entre el lugar y el no-lugar, una ubicación parasitaria, que vive de la imposibilidad misma de estabilizarse. Sin ubicación, no hay instituciones que permitan legitimar y gestionar la producción y la consumición de las obras, pero sin desubicación, no hay una constitución verdadera" (la traducción es nuestra). 
precisamente porque asume de forma singular la paratopía: estar en la frontera que separa la sociedad común de su afuera.

Las modalidades de la paratopía varían según las épocas, ya que el creador siempre explora las brechas que se abren en la sociedad. Así el verdadero escritor será el poeta errante en la Antigüedad, el parásito protegido por las grandes figuras en el siglo XVII, el plebeyo que rechaza el papel que se le asigna en un mundo dominado por la nobleza en el siglo XVIII, o los bohemios que se oponen a los burgueses en el siglo XIX. Cuando la producción literaria se basa en el cumplimiento de cánones estéticos, son las comunidades de artistas más o menos marginales las que son paratópicas, y cuando la creación es asunto más personal, la paratopía se elabora en la singularidad de un desvío biográfico. Si bien puede adoptar distintas formas, con todo es invariante en un principio ya que siempre expresa la pertenencia y la no pertenencia. La imposible inclusión en una topía puede tomar la forma de la paratopía de identidad (mi grupo no es mi grupo, figuras de la disidencia y la marginalidad), espacial (mi lugar no es mi lugar, figuras del exiliado y del nómada), temporal (mi tiempo no es mi tiempo) y lingüística (escribo en una lengua que no es la mía u otra que la preferida por mí) (Maingueneau: 86-90).

El autorretrato que Luiselli se construye en sus entrevistas es sumamente paratópico, pues en ellas la dificultad de encontrar su lugar es un tema recurrente e insiste a menudo en la identidad de extranjera que le confirió su biografía itinerante: "Both in English and Spanish, I have always felt slightly foreign" (Smith: s.p.) ("Tanto en inglés como en español, siempre me he sentido ligeramente extraña"; las traducciones de ésta y las demás citas son nuestras); "I felt like I didn't have the right to be a foreigner, and I was extremely foreign" (Oyler: s.p.) ("Sentía que no tenía el derecho de ser extranjera, y era extremadamente extranjera"); o bien, hablando de Papeles falsos: "I decided to write Sidewalks in order to appropriate a language and a space that was not entirely my own. It was an aspirational gesture on my part: I wanted to become a writer, a Mexican writer, an inhabitant of a city in which I had been born but had never lived, a speaker of a language that had been only a small portion of myself. Writing is a way of writing yourself into the world, I guess" (Reber: 12) ("Decidí escribir Papeles falsos para apropiarme de un idioma y un espacio que no eran totalmente míos. 
Este gesto tenía un objetivo: quería convertirme en una escritora, una escritora mexicana, quería habitar una ciudad en la que había nacido pero en la que nunca había vivido, hablar una lengua que sólo había sido una porción reducida de mí misma. Supongo que escribir es, de alguna manera, escribirse en el mundo"). Esta última cita encierra la paradoja inherente a la paratopía: es su carácter paratópico el que habría incitado a Luiselli a redactar Papeles falsos para "inscribirse" en una sociedad a la cual no pertenece, una iniciativa que desembocó en el resultado inverso, a saber, el refuerzo de dicho carácter.

En los textos de ficción, la paratopía también se elabora a través de una actividad de enunciación, dejando huellas en el enunciado mediante "embragues paratópicos". Entre ellos están los personajes ficticios creados por el autor que materializan el propio desvío constitutivo de éste con respecto a la sociedad. El escritor suele identificarse con cuantos atraviesen y crucen las fronteras trazadas entre grupos sociales, como los judíos, los aventureros, los exiliados, los indígenas de América, que son personajes frecuentes en las novelas modernas y funcionan como embragues que relacionan el texto con la condición del escritor.

Partiendo de estas ideas, resulta significativo que Luiselli haya elegido a Gilberto Owen como referencia y personaje de su obra. Es el prototipo del verdadero escritor porque en la vida real encarnaba distintas formas de paratopía: la de identidad, por su difícil condición de hijo natural que le complicaba situarse en la sociedad común ${ }^{13}$ y, después, por no encontrarse a gusto en su familia política bogotana y por sentirse solo en la ciudad de Nueva York; ${ }^{14}$ la espacial, pues desde joven quiso salir de su mundo, "huir" a otros espacios desconocidos donde tampoco nunca se estabilizó; y la de género, dado que parecía oscilar entre las relaciones homosexuales y las heterosexuales. ${ }^{15}$ Todo esto hace que sea difícil asignar

\footnotetext{
13 Sheridan (2008) lee buena parte de sus proyectos literarios a partir de esta condición.

14 Vázquez Pacheco cita al colombiano Álvaro Bejarano quien asevera que, mediante el alcohol, "Owen se estaba suicidando del fastidio de vivir subvalorado por una familia aplastante por las concepciones burguesas que la signaban" (46).

15 Sheridan dice: "Creo que en su juventud amó también a Xavier Villaurrutia" (76). Sería otro de los rasgos compartidos por Owen y la narradora metadiegética, que mantiene una relación ambigua con otra mujer, Dakota.
} 
al escritor un lugar estable y bien definido dentro de la sociedad común mexicana de principios del siglo xx.

Al convertirlo en un personaje literario, Luiselli destaca precisamente estos rasgos paratópicos e insiste en ellos. Central en el retrato de Owen en Los ingrávidos es su alcoholismo, del que padecía en la realidad pero que en la novela llega a ser tan grave que le provoca una progresiva ceguera y que permite allegar la figura de Owen a la del artista maldito; ${ }^{16}$ se insiste en el rechazo del que es objeto por parte de su esposa que lo ridiculiza ante sus amigas e intenta impedir que vea a sus hijos; y aparece en situaciones embarazosas con sus amigos artistas, declamando sin éxito versos malos en el metro o proponiendo traducciones estrafalarias en un bar. Es cuando inventa estos encuentros entre artistas amigos que Luiselli hace coincidir a Owen con García Lorca. Lo que los reúne en Los ingrávidos no es, por lo tanto, el proyecto de guion de Emilio Amero sino proyectitos e ideas bizarras algo infantiles e intelectualmente deshonestas. En el Nueva York de Luiselli, Federico García Lorca queda peor parado que Owen: como personaje encarna todo lo ridículo de las iniciativas de los artistas sin que lo redima el afecto que la narradora-escritora muestra hacia Owen. Está claro que el poeta andaluz no le interesa y la burla instaura una gran distancia entre él y la narradora-escritora mexicana. De tal manera la novela parece legitimar y dar un lugar central a un escritor relativamente poco conocido (al menos fuera de México) y relativizar la importancia que se confiere a otro muy canonizado. Cuestiona su exagerado entusiasmo por los negros y su inteligente autopromoción mediante su actitud de simpatía con todos, con lo cual se aleja notablemente de los estereotipos más comunes que en México han circulado sobre el poeta (y que han sido estudiados por Luis Mario Schneider [1998]).

Una faceta menos realista y más fantástica de la paratopía de Owen, es que aparece en cualidad de fantasma. Esta imagen remonta a Novela como

16 Pascal Brissette (2005) ha demostrado que el tópico de la maldición literaria, personificada en el escritor preso de sus sufrimientos, destruido por el alcohol, las drogas y con tendencias suicidas, tiene todavía hoy una gran importancia en las representaciones que se suelen asociar con el verdadero artista. Para Brissette, el mito del escritor maldito funciona como un mecanismo de valorización que hace posible, a través de un discurso adecuado, su legitimidad literaria, gracias a la asociación que implica entre grandeza y sufrimiento. 
nube del propio Owen donde decía de manera metaficcional: "Ya he notado, caballeros, que mi personaje sólo tiene ojos y memoria; aun recordando sólo sabe ver. Comprendo que debiera inventarle una psicología y prestarle mi voz. ¡Ah!, y urdir, también, una trama, no prestármela mitológica. ¿Por qué no, mejor, intercalar aquí cuentos obscenos, sabiéndolos yo muy divertidos? Es que sólo pretendo dibujar un fantoche" (171). Muchos años después la imagen del fantoche reaparece en el reverso de una tarjeta postal enviada a Josefina Procopio y fechada el 21 de julio de 1950 en la que aparece el auditorio Robin Hood Dell en Filadelfia:

Es el escenario abierto al trasmundo más completo que se conoce. Los fantasmas de atrás, del Laurel Hill Cemetry, vienen a dar conciertos que aplauden otros fantasmas del gran cementerio Ilamado Filadelfia. Cuando parece que está Ileno el Dell, toman una fotografía y aparece todo vacío porque la placa es insensible a los fantasmas. Yo soy la sombra marcada con X (285). ${ }^{17}$

En el poema "Desvelo" repitió la misma imagen: "Mira, ahora, mi sombra sin cuerpo" (51) y en una carta enviada desde Bogotá a Xavier Villaurrutia en México se lamenta: "Se olvidan de mí —me matan-, luego existo. Nadie mataría a un fantasma" (269). ${ }^{18}$ Son estas imágenes de la sombra y del fantasma que se recuperan en Los ingrávidos pero ya sin carga metafórica alguna ya que Owen realmente pierde peso y se hace borroso. El título de la novela se refiere así a la condición fantasmagórica del personaje que no pesa. ${ }^{19}$ Esta condición contribuye a alejar la novela

17 La condición inasible y fantasmal de Owen ha sido comentada por varios críticos. Antonio Cajero Vázquez reproduce un texto escrito por José Alfredo Hernández con ocasión de la muerte del poeta, publicado en Mar del Sur en mayo-junio de 1952. El obituario dice: “aun estando presente — palidez, gabán y frío permanentes en él_ siempre teníamos la seguridad de ser sólo una imagen de sí mismo [sic], una fotografía, la presencia del evadido" (89). Y Rafael Toriz comentó: "aun en la muerte es congruente con su vocación fantasmal" (79).

18 Vicente Quirarte dice al respecto: "En conjunto, el retrato que los Contemporáneos hacen tras la partida de Owen es el de un fantasma. La idea no le hubiera disgustado: si hay una figura que recorre su poesía, es la de un ser desarraigado, de suprema elegancia espiritual" (2007: 18).

19 De hecho, la flacura de Owen hace que la imagen de fantasma no siempre sea totalmente metafórica. En una carta a Xavier Villaurrutia datada el 3 de agosto de 1928 
del realismo y a acercarla al surrealismo o a la literatura fantástica. ${ }^{20}$ Pero, sobre todo, la condición de fantasma lo sitúa entre la vida y la muerte, lo visible y lo invisible, lo inexistente y lo real, en la frontera entre dos condiciones más nítidas y claras. En este sentido es otro rasgo medular del retrato paratópico que Luiselli construye del poeta.

Si Owen es un narrador y personaje importante en la novela, como ya hemos dicho, el segundo (pero el primero que aparece en la novela) es una mujer anónima que ha vivido en Nueva York y que en el momento de la escritura habita en una casa en la Ciudad de México. Allí ejerce como esposa y madre de dos hijos, una condición que dificulta que llegue a escribir su libro sobre Owen, lo cual se refleja en la índole fragmentaria de la novela, hecha de pequeños pedazos a la manera de un puzle, en breves momentos robados al tiempo. Representado así, este personaje que sugiere numerosos parecidos con la escritora real, es eminentemente común, y está bien anclado en la sociedad mexicana contemporánea. Pero recurriendo a una serie de tópicos literarios y aproximándose a Gilberto Owen, Valeria Luiselli utiliza el dispositivo autoficcional para manipular el referente real (su vida) y reescribir su trayectoria personal para hacerla paratópica.

La historia que la narradora cuenta de cuando era joven en Nueva York incluye una serie de lugares comunes relacionados con el mito de la vida bohemia (ver Popovic 2001): la falta de reconocimiento, la pobreza, la amistad y los excesos de todo tipo serán tópicos mencionados y repetidos desde la primera página de su libro: "En esa ciudad vivía sola en un departamento casi vacío. Dormía poco. Comía mal y sin variar mucho. Llevaba una vida sencilla, una rutina. Trabajaba como dictaminadora y traductora en una editorial pequeña que se dedicaba a rescatar 'perlas extranjeras' que nadie compraba - porque al fin y al cabo estaban destinadas a una cultura insular donde la traducción se abomina por impura" (2014: 12). Más adelante hablará de sus amistades y amores pasajeros y relatará repe-

escribe: "Ya no estoy espantablemente flaco. Peso 125 libras y media. Me peso todos los días en la estación del subway, Cr.Bwy. y 116 St." (261).

20 Esto conecta a su vez con una vena presente en Owen, es decir su surrealismo heterodoxo que, en algunos poemas es "un surrealismo bastante personal, que gusta de expresar en un lenguaje claro y puro temas sabrosamente oníricos" (Segovia: 17). 
tidamente sus estafas, sus mentiras y cómo solía robar objetos. Son manías que le hacen perder su trabajo y que, incrementando su distancia con lo común de los mortales, contribuyen a construir su condición paratópica. Su mitomanía y su cleptomanía son, para este personaje autoficcional, lo que es el alcoholismo para el narrador y personaje Owen.

El que se presente como un doble del poeta a su vez contribuye a aumentar su carácter paratópico, pues de esta forma los rasgos de Owen también inciden en ella misma. De hecho, no sólo se identifica simbólicamente con el poeta sino que los dos se encuentran físicamente: se borran las fronteras lógicas entre espacios y sobre todo entre tiempos lo cual es posible gracias a que también la narradora escritora adquiere ingravidez y se afantasma. En el texto, las coincidencias entre los dos narradores no se limitan a encuentros cara a cara en el metro neoyorquino sino que se establecen en el plano temático a lo largo de la historia. Owen lleva a sus hijos al parque, en el fragmento siguiente el marido de la narradora lleva a los suyos al zoológico (95); Owen tiene un conflicto con su ex mujer, la narradora empieza el fragmento siguiente confesando que no ha hablado con su marido en una semana (2014: 109); Owen juega a las escondidillas con sus hijos, la narradora también. Todas estas conexiones temáticas, por otra parte, van acompañadas de ciertas similitudes físicas. Valeria Luiselli compensa de alguna manera la diferencia de sexo que separa a sus dos narradores acentuando los rasgos somáticos que tienen en común, y haciéndolos envejecer de una forma análoga. La juventud de la narradora se asocia con la flaqueza y el vigor. Los mismos valores se repiten como un eco en el relato retrospectivo de Owen. A la inversa, en la narradora ya madura predomina la sensación de pesadez. Es igual en lo que concierne al poeta mexicano, quien, un cuarto de siglo después de su estancia en Nueva York, ha subido de peso de forma considerable. Afirma la narradora: "Salgo de la cama sólo para darles de comer a los niños. Me miro las piernas, parecen dos trompas de elefante" (123). "Estoy gordo, tan gordo que tengo tetas" (65), deplora por su parte Owen en los primeros instantes de su relato. Además, un análisis de las distintas versiones del libro demuestra que la escritora ha ido afinando cuidadosamente la construcción de este nexo de doble al hilo de sus ediciones. El sintagma nominal "O un fantasma" (74) no figura en la primera edición de la novela, como tam- 
poco el comentario "No recuerdo haber escrito yo eso $[. .$.$] ", que sigue la$ nota de Owen (137). Difícilmente se pueden determinar con certeza las intenciones de un autor, pero en este caso concreto parece claro que la función de las dos adiciones es reforzar la continuidad entre los dos narradores: la primera adición se realiza de tal forma que las primeras palabras del fragmento de Owen prolonguen directamente las últimas palabras del fragmento previo, propio de la narradora; la segunda adición introduce una incoherencia que hace el fragmento ambivalente en la medida en que se vuelve atribuible a ambos narradores, es decir, posiblemente enunciado por el uno como por el otro.

Volviendo a la cuestión de la paratopía: son dos fantasmas los que se cruzan en el subway de Nueva York, un lugar que sugiere ciertas connotaciones paratópicas porque limita el mundo de arriba, de los vivos y lo visible, y el mundo de abajo, de la muerte y lo invisible, y porque, así sugieren Owen en su correspondencia y Luiselli en su novela, permiten ver el mundo desde una perspectiva alternativa, fuera de lo común. El cariño que le tiene Owen al metro neoyorquino se deduce de una carta que escribió el 22 de abril de 1929 a su amigo Xavier Villaurrutia y donde decía: "Quisiera presentarte a mi subway. Tenemos la misma edad, dicen unos carteles que he visto, nacidos tú, él, Salvador y yo en 1904, déjame decirnos generación de sub bueyes, fácilmente muertos" (263-264). Pero es en otra carta anterior, fechada el 7 de septiembre de 1928 y dirigida a Celestino Gorostiza, donde Owen se explayaba sobre cómo hay que cambiar las perspectivas y mirar las cosas desde abajo, es decir, desde el metro:

Los que siguen siendo extranjeros son los que van a ver a New York desde la torre del Woolworth. Tienen así de esto una idea literaria, menos aún, periodística, de plano para turistas. A New York se la empieza a ver desde el subway. Acaba allí la perspectiva plana, horizontal. Empieza un paisaje de bulto ahí, con la doble profundidad, o eso que llaman cuarta dimensión, del tiempo (270). ${ }^{21}$

21 El texto de Owen titulado "Autorretrato o del subway" analizado en profundidad por Anthony Stanton, incluye otra alusión al fantasma: "fantasma anochecido de aquel río que se soñaba encontrado en un solo cauce" (65). En la carta a Xavier Villaurrutia del 28 de julio de 1928 habla de él: "Mi subway está muy adelantado. Estoy haciendo, con Amero, una película. Creo que va a ser algo digno de mi grupo" (260). Según Vicente Quirarte es el único poema conocido de su relación con la ciudad de Nueva 
Luiselli conoce estas reflexiones, pues se refiere a ellas en su reseña sobre Owen en Letras Libres, y parte de ellas para situar sus encuentros fugaces con Owen en el metro neoyorquino. Uno de los comentarios de su álter ego ficcional incluso se refiere a este vuelco de perspectiva: "Una novela vertical, contada horizontalmente. Una historia que se tiene que ver desde abajo, como Manhattan desde el subway" (2014: 128). Este vuelco de perspectiva parece igualmente hacer eco al método de exploración adoptada por Luiselli en Papeles falsos: la autora intenta primero ver la Ciudad de México desde arriba, pero constata que "el segundo piso del Periférico no ofrece más que un breve salir a respirar a la superficie, en medio de [las] cotidianas pataditas de ahogado" (2010: 33-34), razón por la cual decide volver a ras de tierra y se pone a viajar a través de las calles de la capital. Como Manhattan, México debería verse "desde abajo". Al mismo tiempo remite a Owen en cuyo poema titulado "Perfil", el primero de los dos poemas numerados de "Autorretrato o del subway", se plantea la cuestión de la perspectiva y se integran las categorías de lo horizontal y lo vertical (Stanton: 746).

Mediante las referencias a Owen y sus encuentros imaginados con él en Nueva York, Luiselli hace lo que hace cualquier escritor: inscribirse en una tribu de su elección, la de los escritores que sitúa en su panteón personal y cuyo modo de vida y obra le permiten legitimar su propia enunciación. Si bien en su trayectoria hay varios escritores que desempeñan esta función (Brodsky es otro de los importantes, pero también Rulfo lo es), en Los ingrávidos sobre todo se presenta como una admiradora de Owen. De esta forma se aprovecha del carácter altamente paratópico del poeta para construir su legitimidad de escritora. Al asociarse con él elabora una postura de escritor, una "manera singular de ocupar una posición en el campo literario" (Meizoz: 18). Como Owen, Luiselli parece manifestar el deseo de alejar su obra de ficción de las circunstancias nacionales que considera más tópicas. Su postura de escritora "desarraigada" o "desvinculada" es reforzada mediante la identidad de extranjera que se atribuye en diversas entrevistas y encuentra una expresión metafórica en la figura del fantasma.

York y en él ve coincidencias con la obra de García Lorca: "su imaginería recuerda los poemas de García Lorca escritos a partir de la misma experiencia: imágenes aisladas, superpuestas, como aires de jazz o composición de Gershwin" (2007: 72). 
Asimismo, el carácter esquivo y difícilmente asible de Owen, su ubicación fuera de las tendencias más conocidas sirve como contrapeso para la inscripción de Los ingrávidos en el género de la autoficción que, en las últimas décadas, se ha llegado a practicar hasta tal punto que se ha convertido, a los ojos de sus críticos más escépticos, en un formato excesivamente comercial.

\section{Bibliografía}

Barbosa Vera, E. y Pablo Scofaulos. "Hiperrealismo afantasmado. Entrevista a Valeria Luiselli" (2012). Artículo en línea disponible en: <https://revistatonica. com/2012/10/10/hiperrealismo-afantasmado/> [consultado el 5 de junio de 2017].

Bauman, Zygmunt. Liquid Modernity. Cambridge: Polity, 2000.

BRISSETTE, PASCAL. La malédiction littéraire. Du poète crotté au génie malheureux. Montréal: Presses de l'Université de Montréal, 2005.

Cajero Vázquez, Antonio. Gilberto Owen en Estampa. Textos olvidados y otros testimonios. San Luis Potosí: El Colegio de San Luis, 2011.

Colonna, Vincent. Autofiction et autres mythomanies littéraires. Auch: Tristram, 2004.

Domínguez Michael, Christopher. Antología de la narrativa mexicana del siglo XX, t. I. Selec., introd. y notas de C. D. M. México: Fondo de Cultura Económica, 1989 (Letras Mexicanas).

Domínguez Michael, Christopher. "Dos cajas de Valeria Luiselli", en Letras Libres. XVI-182 (febrero de 2014): 68-70.

Elvridge-Thomas, Roxana (comp.). Gilberto Owen. Con una voz distinta en cada puerto. México: Tierra Adentro, 2004.

GonzÁlez ArCe, Teresa. "Del ensayo a la novela. Los procesos autoficcionales de Papeles falsos y Los ingrávidos de Valeria Luiselli", en Sincronía. Guadalajara, XX-69 (enero-junio de 2016): 254-268.

GonzÁlez MuñIz, Carlos. "Novela como nube: el caso de la narrativa de vanguardia en México", en Roxana Elvridge-Thomas (comp.). Gilberto Owen. Con una voz distinta en cada puerto. México: Tierra Adentro, 2004. 145-169.

Kellman, Steve. The Self-Begetting Novel. Londres: MacMillan, 1980.

Luiselli, Valeria. "Gilberto Owen, narrador", en Letras Libres. México, XI-121 (enero de 2009a): 58-59.

Luiselli, Valeria. "Toni Morrison. Nobel 1993", en Letras Libres. México, XI-124 (abril de 2009b): 57-59.

Luiselli, Valeria. Papeles falsos. México: Sexto Piso, 2010.

LUISELLI, VAleRIA. "Novedad de la narrativa mexicana II: Contra las tentaciones de la nueva crítica" (2012). Artículo en línea disponible en: <http://www.nexos. com.mx/?p=14682> [consultado el 18 de abril de 2017].

Luiselli, Valeria. Los ingrávidos [2011]. México: Sexto Piso, 2014. 
Maingueneau, Dominique. Le discours littéraire. Paratopie et scène d'énonciation. París: Armand Collin, 2004.

Marín, Sigifredo E. "Homo viator: metáforas de la errancia en Gilberto Owen", en Roxana Elvridge-Thomas (comp.). Gilberto Owen. Con una voz distinta en cada puerto. México: Tierra Adentro, 2004. 53-70.

Meizoz, Jérôme. Postures littéraires. Mises en scène modernes de l'auteur. Ginebra: Slatkine, 2007.

Monegal, Antonio. "Introducción”, a Federico García Lorca. Viaje a la luna. Valencia: Pre-textos, 1994. 6-40.

Orejas, Francisco. La metaficción en la novela española contemporánea. Entre 1975 y el fin de siglo. Madrid: Arco Libros, 2003.

Owen, Gilberto. Obras [2 ${ }^{a}$ ed. aumentada; primera, 1953]. Edición de Josefina Procopio. México: Fondo de Cultura Económica, 1979 (Letras Mexicanas).

Oyler, Lauren. "Valeria Luiselli: the Novelist All Your Smart Friends Are Talking About" (2015). Artículo en línea disponible en: <https://broadly.vice.com/ en_us/article/valeria-luiselli-the-novelist-all-your-smart-friends-are-talkingabout> [consultado el 30 de enero de 2017].

PAPE, MARÍA. "El pasaje como modus operandi: perspectivas simultáneas y recíprocamente excluyentes en Los ingrávidos de Valeria Luiselli", en Revista Chilena de Literatura. Santiago, 90 (septiembre de 2015): 171-195.

Popovic, Pierre. "Bohème", en Paul Aron, Denis Saint-Jacques y Alain Viala (dirs.). Le dictionnaire du littéraire. París: Presses Universitaires de France, 2001. 62-63.

Quirarte, Vicente. "Introducción" a Gilberto Owen. Novela como nube. México: Universidad Nacional Autónoma de México, 2004. VII-XIII.

QUIRARTE, VICENTE. Invitación a Gilberto Owen. México: Universidad Nacional Autónoma de México, 2007.

ReBER, NiCHOLE L. "Writing Yourself into the World: A Conversation with Valeria Luiselli", en World Literature Today. Norman, XC-1 (enero-febrero 2016): 12-15.

SChNeIder, Luis MARio. García Lorca y México. México: Universidad Nacional Autónoma de México, 1998.

Segovia, Tomás. Cuatro ensayos sobre Gilberto Owen. México: Fondo de Cultura Económica, 2001 (Letras Mexicanas).

Sheridan, Guillermo. Tres ensayos sobre Gilberto Owen. México: Universidad Nacional Autónoma de México, 2008.

SMith, Wendy. "An International Life In Essays and Fiction: Valeria Luiselli" (2014). Artículo en línea disponible en: <http://www.publishersweekly.com/pw/ by-topic/authors/profiles/article/62009-an-international-life-in-essays-and-fiction-valeria-luiselli.html> [consultado el 30 de enero de 2017].

StANTON, ANTHONY. "Un poeta mexicano se apropia de las vanguardias europeas en Nueva York: 'Autorretrato o del subway' de Gilberto Owen", en Revista Iberoamericana, LXXIV-224 (2008): 741-750.

TORIz, Rafael. "El rostro de arena", en Roxana Elvridge-Thomas (comp.). Gilberto Owen. Con una voz distinta en cada puerto. México: Tierra Adentro, 2004. 79-84. 
Usı, Eva. "Los ingrávidos, de Valeria Luiseli, aclamada en Berlín" (2013). Artículo en línea disponible en: <http://www.dw.com/es/los-ingrávidos-de-valeria-luiselli-aclamada-en-berlín/a-16878999> [consultado el 31 de enero de 2017].

Vázquez Pacheco, Claudio. Gilberto Owen. Dos encuentros. México: Universidad Nacional Autónoma de México, 2015.

Velasco, PaOla. "Apuntes a Novela como nube", en Roxana Elvridge-Thomas (comp.). Gilberto Owen. Con una voz distinta en cada puerto. México: Tierra Adentro, 2004. 183-192.

Kristine VAnden BerGHe

Es profesora de literaturas hispanoamericanas en la Universidad de Lieja. Se interesa especialmente por la prosa hispanoamericana de los siglos xx y xxı. En cuanto al género de la autoficción, ha publicado sobre la obra de NeIlie Campobello, César Aira, Alan Pauls, Héctor Abad Faciolince, Fernando Vallejo y el Subcomandante Marcos.

NiCOLAS LICATA

Inició recientemente un doctorado en Lenguas, Letras y Traductología en la Universidad de Lieja, Bélgica. Su investigación se centra en las autoficciones fantásticas mexicanas y argentinas de los últimos veinte años (19932014). Con comunicaciones relativas a este tema ha participado en varios coloquios en Bélgica, Alemania, España y México. 